\title{
Nursing Education and Service Collaboration: Making a Difference in the Clinical Learning Environment
}

Sheri P. Palmer

Brigham Young University - Provo, sheri_palmer@byu.edu

Amy Harmer Cox

Brigham Young University - Provo

Lynn Clark Callister

Brigham Young University - Provo

Vickie Johnsen

Geraldine Matsumura

Follow this and additional works at: https://scholarsarchive.byu.edu/facpub

Part of the Other Nursing Commons

\section{Original Publication Citation}

Palmer, S., Cox, A. H., Callister, L. C., Matsumura, G., \& Johnsen, V. (2005). Nursing education and service collaboration: Making a difference in the clinical learning environment. Journal of Continuing Education in Nursing, 6(36), 271-276.

\section{BYU ScholarsArchive Citation}

Palmer, Sheri P.; Cox, Amy Harmer; Callister, Lynn Clark; Johnsen, Vickie; and Matsumura, Geraldine, "Nursing Education and Service Collaboration: Making a Difference in the Clinical Learning Environment" (2005). Faculty Publications. 5325.

https://scholarsarchive.byu.edu/facpub/5325

This Peer-Reviewed Article is brought to you for free and open access by BYU ScholarsArchive. It has been accepted for inclusion in Faculty Publications by an authorized administrator of BYU ScholarsArchive. For more information, please contact ellen_amatangelo@byu.edu. 


\title{
Nursing Education and Service Collaboration: Making a Difference in the Clinical Learning Environment
}

\author{
Sheri P. Palmer, RN, MSN, Amy Harmer Cox, APRN, MS, Lynn Clark Callister, RN, PhD, FAAN, \\ Vickie Johnsen, RN, PhD, and Geraldine Matsumura, APRN, PhD
}

\section{ABSTRACT}

This article focuses on innovative collaborative steps that were identified in recent research conducted by these authors on the relationship between academia and service. These steps are currently being implemented in the hope of improving the important role that the clinical environment plays in student nurses' education. Few factors in nursing education are as important as the clinical environment in which students do their training. This article elaborates on these steps and offers practical suggestions for improving the relationship between academia and service.
Tmproving the clinical teaching environment is a conLstant ambition among nursing academia. Through research and innovative steps, various strategies have been implemented in the clinical realm of nursing education. The effects of these strategies are currently being studied, and where necessary are being changed, to make a positive difference in the clinical learning environment.

\section{REVIEW OF LITERATURE}

Studies suggest the importance of the clinical environment in relation to the education of the student nurse is of utmost concern (Dunn \& Burnett, 1995; Grams, Kosowski, \& Wilson, 1997; Paterson, 1997). Acknowledging that the clinical environment is important, studies on nursing students' perceptions about their clinical experience and education are essential and gaining momentum.

An Australian study measured undergraduate nursing students' perceptions of their clinical learning environment (Dunn \& Hansford, 1997). The Clinical Learning Environment Scale (CLES) (Dunn \& Burnett,

Ms. Palmer is Assistant Teaching Professor, Ms. Cox is Assistant Teaching Professor, and Dr. Callister is Professor, the College of Nursing, Brigham Young University, Provo, Utah. Dr. Johnsen is Nurse Administrator, Intermountain Health Care, Salt Lake City, Utah. Dr. Matsumura is in private practice in Salt Lake City, Utah.

Address correspondence to Sheri P. Palmer, RN, MSN, Assistant Teaching Professor, Brigham Young University College of Nursing, Box 500, SWKT, Provo, UT 84602.
1995) was completed by the 229 undergraduate nursing students participating in the study. In addition, focus groups of students were held. During the course of the study, specific attributes emerged that have a significant impact on the clinical environment. Findings related the importance of staff nurse attitudes, organizational policies, and student characteristics.

Many studies suggest that staff nurse attitudes contributing to a positive clinical learning environment include warmth and rapport, support in gaining access to learning experiences, and the willingness of staff to engage in a teaching relationship. Organizational policies contributing to a positive clinical learning environment included valuing educating students, the clinical venue's awareness of the students' learning needs, and skills of the registered nurse staff both in patient care and teaching abilities and in the manner in which students' patient assignments are arranged. According to Dunn and Hansford (1997, p. 1299), "The clinical learning environment (CLE) influences the development of student attitudes, psychomotor skills, knowledge, and clinical problem solving abilities."

In 1995, an English study was conducted that focused on registered nurses' experiences mentoring undergraduate nursing students (Atkins \& Williams, 1995). In this study, researchers concluded that mentoring student nurses is a complex activity requiring a high degree of skills, including educational preparation, support, and recognition. 


\section{TABLE 1}

\section{ADVICE TO STAFF NURSES}

- Assess your feelings about working with student nurses.

- Become knowledgeable about the students you work with.

- Gain a collegial relationship with clinical faculty.

- Synergize your efforts: Teach and give patient care simultaneously.

- Communicate with faculty and students your expectations when the unit gets extra busy and you are on overload.

- When the unit is quiet, look for alternative learning experiences. What is routine to you is not routine or simple for the student.

- Effectively communicate with students and clinical faculty to work through challenges.

- Share the most important characteristics of your practice: Advocacy, critical thinking, and a love for nursing.

Data from Loring, C. F. (1999). Do nurses really eat their young? Association of Womens Health, Obstetric, and Neonatal Nursing, 3(1), 47-50.

The range of student experiences with various staff nurses was identified in a study by Loring (1999). They invited current staff nurses to recall their experiences when they were students. The nurses explained various types of educative experiences in the clinical environment and spoke of the difference between "the nurse who gave you your report and then was missing in action for the rest of the morning" and "the nurse who said, 'I really love to teach' and meant it" (p. 47). This type of difference between staff nurses is a common phenomenon among most studies. Loring has identified helpful and practical suggestions for staff nurses working with students that are adapted and are summarized in Table 1.

Colleagues in Caring reports on 6 years of collaborative efforts between nursing service and education (Rice, 2003). Rice notes that there are major philosophical differences between nursing service and education, including the differences between the "ideal" and the "real" world of clinical practice. Nurse educators think in terms of semesters and programs, and those in nursing service think in terms of meeting the pressing needs of today. Rice also suggests that a willingness to work together, gaining mutual understanding, and having a sense of humor are essential to collaborative efforts. The report concludes that "collaboration will continue to be critical in the continuing search for solutions in the future" (Rice, 2003, p. 148). Other than the Colleagues in Caring report, there is a paucity in the literature describing staff nurse perceptions of the contributions of students and the importance of a positive clinical learning environment.

\section{DESCRIPTION OF INNOVATIVE COLLABORATIVE EFFORTS}

\section{The Impetus Behind the Project}

It has been a challenge to both the College of Nursing and the surrounding health care agencies to feel cohesion in the educative efforts of the nurses. Furthermore, the lack of abundant studies on the perceptions of students and nurses and related topics prompted these authors to study these issues in local hospitals. It was believed that if the service agencies could be surveyed as to how nursing students are perceived, a greater commonality and collegiality in education might evolve. This prompted a research study that surveyed staff nurses regarding their perceptions of the benefits of working with nursing students.

The Nursing Students' Contributions to Clinical Agencies scale, developed by Grindel, Bateman, Patsdaughter, Babington, and Medici (2001), was used. This survey focuses on the effects undergraduate nursing students have on staff time, development, quality of care, personal satisfaction, and unit standards and practices. Two hundred twenty-five nurses working in four different clinical agencies and a variety of settings participated in the study.

The questionnaire was based on a Likert-type scale. The participants rated their overall perceptions of students' contributions from -5 (extremely negative) to +5 (extremely positive). The general result or mean perception was 2.56 . Although the result (2.56) was not negative, it was interesting to note that there can be much room for improvement.

Staff nurses need to perceive more positive aspects from their relationship with student nurses. This was also identified with the high correlation between positively framed items such as "allows opportunities for mentoring" and negatively framed items such as "do not appreciate the support of staff nurses" ( $r=.432^{* *}$, $p=.000)$. These correlations indicate that the nurses have ambivalent feelings about the benefits of having students on the unit. This was further evidenced by the two highest scored items of the survey being "allows opportunities for mentoring" (mean of 3.248) and "threatens professional role development" (mean of 3.171).

Ambivalence regarding the benefits and challenges of working with student nurses was not only documented in the quantitative findings, but also expressed in narrative comments in response to an open-ended 
question added to the survey to allow for additional comments regarding staff nurses' experiences with students. This ambivalence is reflected in a narrative statement from one study participant:

Although all students need experience, it takes a toll on the nursing staff. It takes more time to deal with students and this can take away from patient care. Some students are great. Those that are not self-motivated make teaching them very difficult!

Another study participant who was a critical care nurse and student mentor wrote:

Some [students] are extremely good, know their limits and how to work with them, and others are very tentative. Some will do vital signs and other things on schedule. Others have to be watched or you find out things you thought were being done weren't. It's very frustrating to have students who cause you to take twice as long to get work done because they are too worried, scared, or just haven't had enough practiceas in drawing up medications and taking forever.

\section{The Collaboration of Ideas Between Service and Education}

This ambivalence expressed by staff nurses indicates the need to develop strategies to promote collegial relationships between staff nurses and students. The findings of this study were presented to College of Nursing faculty and to the nurse managers at the four facilities where the study was conducted. Administrative personnel in one of these four facilities (a Level II acute care facility) were interested in a continuing collaboration to improve relationships between nursing service and nursing education and to enhance the quality of the student mentoring experience for both students and the nurses.

The following assumptions identified by Birx and Baldwin (2002) and through our own observations are guiding this collaborative effort:

1. Clinical learning is essential for student nurses. The foundation of adequate clinical experiences for the student is the key to success in a nursing education program.

2. Staff nurses make a tremendous difference in the quality of the clinical learning environment. The staff nurse who is genuinely interested in the quality of students' education can provide an atmosphere of quality learning. This is done by forging a trusting, professional relationship.
3. Mentoring students is an essential component of the role of staff nurses. There are many advantages noted from effective mentoring relationships in professional settings. Staff nurses are realizing that mentoring is a key component to advance the profession as a whole.

4. Opportunities for meaningful mentoring can increase professional satisfaction for staff nurses. Being an active part of growth and education in educating future nurses can increase personal and professional identity and satisfaction. Resulting feelings of positive self-worth can foster a sense of accomplishment both in and out of the workplace.

Through joint sessions with educators and clinicians held on a continuing basis (at least bi-monthly), there was much discussion on what could be done to improve the quality of the experience for everyone. Suggestions made by the unit managers for nurse educators and students are listed in Table 2.

Following the presentation of these data and the discussion of the implications of the survey to the managers and other nurse administrators, interviews were done with staff nurses regarding their experiences mentoring students. Questions included: "What makes your experiences with students positive/rewarding?", "When you were a student, what specific behaviors did your mentors practice that enhanced your [clinical] experience?", "What is it about the students' experiences here that would attract them to come here full-time post graduation?", and "What resources do you need to be more effective as a mentor?"

Results of these interviews show that many nurses enjoy working with students who are engaged completely in learning and providing quality nursing care by asking for assistance appropriately. This is portrayed in the following comment from one student:

The nurses that I had were really helpful in making sure that I had the experiences I needed as a student. One nurse asked me specifically if there was something I wanted to do that I hadn't done yet. At that time I hadn't ever performed a vaginal exam and it was my last day, so I told her that this had been one of my goals. She made sure my nurse. . and that every other nurse knew so that I would have the opportunity if it ever arose. All the nurses were really great about making sure I got to see or do procedures that were out of the ordinary and they all tried to find me when these special situations occurred. I really appreciate the willingness and helpfulness of all the nurses that I worked with! 


\section{TABLE 2}

SUGGESTIONS FOR IMPROVING THE QUALITY OF CLINICAL LEARNING EXPERIENCES FOR NURSES AND STUDENTS

1. Students need to do complete nursing care for their patients as much as is feasible given their skills level.

2. Staff should be provided with information on the current skill level of students and their learning objectives for specific clinical days.

3. Students should be scheduled at the beginning of the shift and attend report so they are integrated as members of the health care delivery team.

4. Faculty and staff nurse and students assigned to the patient should hold end-of-shift conferences.

5. Students need more clinical time and less emphasis on paperwork (written assignments), especially while on the unit.

6. Faculty need to be the MAJOR source of student teaching at the clinical level instead of sometimes less experienced and less educationally prepared staff nurses. Roles in clinical teaching should be negotiated between faculty, unit managers, and staff nurses because faculty are facing increasing work loads and increasing demands for scholarly productivity. Faculty challenges are also documented in the literature (Paterson, 1997; Schuster, Fitzgerald, McCarthy, \& McDougal, 1997).

7. Staff nurses should be provided with information on how to effectively mentor student nurses.

Nurses noted that there were both challenges and satisfaction in working with nursing students. Nurses appreciate clinical faculty actively engaged in teaching their students and assisting with patient care. Nurses especially enjoy participating in preceptorships because it gives them the opportunity to get to know one student in depth. Nurses are grateful when their efforts in mentoring students are acknowledged and appreciation expressed. These ideas confirmed the findings of various authors reported in the literature cited within this article.

\section{THE COLLABORATION PROJECT}

The results of these interviews were presented to a working group of nurse educators, nurse administrators, and nurse managers. Two hospital units were selected as pilot units to employ suggested educational interventions: a maternal-newborn unit and a medical-surgical unit with a high acuity. The following strategies designed to improve staff nurse-student relationships are being implemented.

First, these two units will begin staff education "highlights" on how to effectively mentor nursing students as part of staff meetings. Potential topics for the highlights include "Helping Students Feel Part of the Health Care Team," "Creating a Positive Clinical Learning Environment," "Explaining Difficult Concepts," "Balancing Meeting Patient Needs and the Learning Needs of Students: How Can I Do It All?," "What To Do When Supporting and Assessing Students' Conflict?," and "Effectively Providing Feedback to Students." Data will be collected prior to and following these efforts to assess the effective- ness of this educational intervention. The essential requirements of successful mentoring relationships will be discussed based on the literature on mentoring in nursing, including mutual respect and the investment of time and energy (Atkins \& Williams, 1995; Olson \& Vance, 1999; Vance, 2002; Vance \& Olson, 1998).

Making such discussions a regular part of staff meetings will provide the opportunity to address concerns and continually improve mentoring. It will provide direction to nurses as they establish personal goals for mentoring students. Letizia and Jennrich's (1998) review of the literature on preceptorship may be foundational for a beginning discussion.

A series of clinical scenarios and case studies are being developed that will be used to guide discussions in staff meetings. An example of a teaching scenario entitled "Encourage Critical Thinking in Clinical Situations Through the Use of Questions" is outlined in the sidebar. Another scenario focuses on "Creating a Learning Environment: Making It Safe to Ask Questions." Staff nurses are asked to generate a list of effective practices to encourage students to ask questions, to role play being the staff nurse or the student with a peer, and then to select two methods to encourage students to ask questions and implement them for 2 weeks.

Second, both staff nurses and students will complete evaluation forms of their experience. Because daily evaluations were deemed burdensome by the staff, periodic evaluations are being done a few times each semester. These forms are developed through collaborative efforts of the nurse managers and educators. 


\section{Sample Teaching Scenario \\ ENCOURAGE CRITICAL THINKING IN CLINICAL SITUATIONS THROUGH THE USE OF QUESTIONS}

Setting: Staff meeting

Purpose: To teach staff nurses/mentors who work with students basic concepts to effectively interact in the learning environment. Critical thinking elements will be utillzed. One of the ways we promote critical thinking is through the dynamic interaction of questions and answers. Staff nurses can learn and practice effective questioning techniques.

Materials: Pencil and paper

Facilitator: Remember your last experience or shift with a student. Think of the patient assignment you had together. Now make three columns on your paper (Recognize data). List in the first column one or two challenges that the patient(s) encountered during the shift (i.e., the patient had a high fever and was immunosuppressed). In the second column, note a few challenges you personally had during the shift (i.e., the nurse felt extremely overloaded due to high patient acuity). Finally, in the third column note a few challenges you believe the student had during the shift (i.e., the student had limited knowledge of immunosuppressed patient care).

Now look at the three columns and ask yourself: (Synthesize data)

- Are any of the challenges the same or similar? What made them similar, or why were they the same (i.e., the fact that the immunosuppressed patient had a high fever heightened his acuity and the nurse was already feeling overloaded due to the high acuity of the other patients. The student had limited experience with immunosuppression).

- What was the outcome of these challenges? Were there any that went unresolved?(i.e., due to the anxiety of the staff nurse the student was "left out of the loop" while the nurse hurriedly contacted the physician, received appropriate orders, ordered laboratory work-ups, and called the pharmacist. The student, feeling the tension, retreated to a "safe spot" by the desk).

- Were you aware of these challenges at the time? (i.e., the nurse knew the importance of making quick clinical decisions in this situation. He or she did feel extra stressed with this added problem on an already hectic day. In addition, the nurse felt that he or she was probably not including the student, but "there just wasn't time").

(Ask for volunteers to share if possible)

Now picture yourself with a new student with these same challenges in front of you. What are some of the questions you could ask the student to help him/her be more involved from the start of a similar situation? (Management of data)

(Ask for suggestions)

Make sure questions cover the areas of recognition of problems, possible management of problems, rationale to support actions, urgency in management, and assessment of outcomes (i.e., staff nurse to student: "Do you know why a fever is a significant sign in an immunosuppressed patient?" "What do you think we should do about it?" "What do you suspect the physician may want us to do?" "When do you think we should carry out these orders?" and "How do you think the situation was handled, and what was the patient outcome?" "Could we have done anything better?"). (Assessment of data)

It may help to role play a situation with the staff nurses. Have a staff member be the student and another act as the "nurse." It is important to show that the nurse can still perform his/her tasks, while including the student by asking questions. Emphasize that inclusion by asking questions is an important mentoring process, thus improving the shared experience and enhancing critical thinking.

Third, clinical faculty will be engaged in a staff meeting at the beginning of each semester. The presence of a faculty member in the staff meeting opens up lines of communication where concerns can be voiced and further strategies formulated. Furthermore, to enhance communication, content for the College of Nursing communication skills laboratory for beginning students is also being revised to provide opportunities for students to learn how to communicate more effectively with staff nurse mentors.

Finally, in addition to these efforts, the College of Nursing has begun a program of regular recognition for clinical nurses who are excellent mentors in all of our clinical agencies. In our experience, simple recognition and expressions of appreciation are significant motivators.

\section{DISCUSSION}

The caring imperative is becoming increasingly emphasized in mentorship relationships because promoting the growth of another is of primary importance (Scotto, 2003). Creating a culture that fosters "human potential, professional development, and mutual understanding" (Atack, Comacu, Kenny, LaBelle, \& Miller, 2000, p. 287) is the goal of the collaborative effort described in this article.

Participation in nursing education should be an expected and valued part of the role of the professional nurse. According to the American Nurses Association standards of practice (2004, p. 37), "The registered nurse interacts with and contributes to the professional development of peers and colleagues" and "[t]he registered nurse contributes to an environment that is 
conducive to the education of health care professionals." The integration of students as fully participating members of the health care team can make an important difference in the quality of the clinical learning environment. As staff nurses have the opportunity to mentor meaningfully and are provided with the skills to do so, the clinical learning environment will be enhanced. Mentoring may be one of the highest forms of leadership (Lockwood-Rayermann, 2003; Vance, 2002).

The authors have a vision for the long-range implications of collaborative efforts. As educators and clinicians, we have the sense that an improved clinical learning environment will also improve morale on the unit, increase job satisfaction as staff have the opportunity to mentor meaningfully, and contribute to recruitment and retention efforts. Early reports show an increased cohesiveness as students and staff nurses seem more like "colleagues." Agencies participating in the collaboration have a renewed interest in the education process of the nurse and a vested interest in the quality of the nursing graduate. Interest in the education of the future nurse is starting from the staff nurse level and working "upwards" toward higher levels of administration. This is an innovative and reversed approach to include much needed involvement from the service agencies.

More data are needed to document the outcomes growing out of collaborative efforts between education and service. Follow-up studies are needed that measure staff nurse perceptions after collaborative efforts are in place. Leadership, critical thinking, and assessment of technical skills among staff nurses and students alike would be valuable assessments before and after collaborative efforts. Ultimately, however, collaboration between nursing education and nursing service is essential to more effectively meet the needs of both staff nurses and undergraduate nursing students learning and growing together.

\section{REFERENCES}

American Nurses Association. (2004). Nursing: Scope and standards of practice. Washington DC: Author.

Atack, L., Comacu, M., Kenny, R., LaBelle, N., \& Miller, D. (2000). Student and staff relationships in a clinical practice model: Impact on learning. Journal of Nursing Education, 39, 387-392.

Atkins, S., \& Williams, A. (1995). Registered nurses' experiences of mentoring undergraduate nursing students. Journal of Advanced Nursing, 21, 1006-1015.

Birx, E., \& Baldwin, S. (2002). Nurturing staff-student relationships. Journal of Nursing Education, 41, 86-88.

Dunn, S. V., \& Burnett, P. (1995). The development of a clinical learning environment scale. Journal of Advanced Nursing, 22, 1166-1173.

Dunn, S. V., \& Hansford, B. (1997). Undergraduate nursing students' perceptions of their clinical learning environment. Journal of Advanced Nursing, 25, 1299-1306.

Grams, K., Kosowski, M., \& Wilson, C. (1997). Creating a caring community in nursing education. Nurse Educator, 22, 10-16.

Grindel, G. G., Bateman, A. L., Patsdaughter, C. A., Babington, L. M., \& Medici, G. (2001). Student contributions to clinical agencies. Nursing and Health Care Perspectives, 22, 197-202.

Letizia, M., \& Jennrich, J. (1998). A review of preceptorship in undergraduate nursing education: Implications for staff development. The Journal of Continuing Education in Nursing, 29, 211-216.

Lockwood-Rayermann, S. (2003). Preceptor style and the nursing practicum. Journal of Professional Nursing, 19, 32-37.

Loring, C. F. (1999). Do nurses really eat their young? Association of Womens Health, Obstetric, and Neonatal Nursing, 3(1), 47-50.

Olson, R., \& Vance, C. (1999). Mentoring in nursing education. In K. Stevens \& V. Cassidy (Eds.), Evidence-based teaching: Current research in nursing education (pp. 23-69). Sudbury, MA: Jones \& Bartlett.

Paterson, B. L. (1997). The negotiated order of clinical teaching. Journal of Nursing Education, 36, 197-205.

Rice, R. B. (2003). Collaboration as a tool for resolving the nursing shortage. Journal of Nursing Education, 42, 147-148.

Schuster, P., Fitzgerald, D. C., McCarthy, P. A., \& McDougal, D. (1997). Work load issues in clinical nursing education. Journal of Professional Nursing, 13, 154-159.

Scotto, C. J. (2003). A new view of caring. Journal of Nursing Education, 42, 289-291.

Vance, C. (2002). Leader as mentor. Nursing Leadership Forum, 7 , 83-90.

Vance, C., \& Olson, R. K. (1998). The mentor connection in nursing. New York: Springer.

\begin{tabular}{|ccccc|}
\hline \multicolumn{5}{c|}{ CE QUIZ ANSWERS } \\
1.C & 2.A & 3. D & 4. C & 5.B \\
6. A & 7.D & 8. B & $9 . B$ & $10 . \mathrm{C}$ \\
\hline
\end{tabular}


Copyright of Journal of Continuing Education in Nursing is the property of SLACK Incorporated and its content may not be copied or emailed to multiple sites or posted to a listserv without the copyright holder's express written permission. However, users may print, download, or email articles for individual use. 